\title{
Factors Affecting the Implementation of Tutorial Class for Fresh Female Students: The Case of Agricultural Science Faculty, Bule Hora University
}

\author{
Ahmedin Abdurehman $^{1 *} \quad$ Abinet Bekele $^{2}$ \\ 1.Department of Animal Science Oda Bulum University, P.O. Box 226, Chiro, Ethiopia \\ 2.Department of Plant Sciences, Bule Hora University, P.O. Box 144, Bule Hora, Ethiopia
}

\begin{abstract}
It is known that educating female is educating society thus why more attention was given for female students in their academic performance. The main purpose of this study was to investigate the factors affecting implementation of first year female student's tutorial in Agricultural Science Faculty which may direct female students' for low academic performance and high attrition. The findings of the study indicated that the problems female students encounter in Bule Hora University specially in Faculty of Agricultural science constitute personal, environment, economic and family related problems. The factors that affect female students' academic performance and cause high attrition are categorized in the same way as problems of female students encounter. They include personal matters, lack of self-confidence, lack of adequate effort, carelessness, lack of ability to be competent and previous academic background in high school. In conclusion, the majority of problems female students encounter and those factors that affect female students' academic performance are personal and the other problems are caused by the university environment. Furthermore, the factors that affecting implementations of tutorials and thus affect the attrition rates of female students.
\end{abstract}

Keywords: Female, student, tutorial

DOI: $10.7176 / \mathrm{JCSD} / 46-05$

Publication date:March $31^{\text {st }} 2019$

\section{INTRODUCTION}

Gender disparity in education in terms of enrollment, completion rate, dropout rate and the like are characteristics of many African countries. The existence of such gender inequalities and injustice are the most persistent obstacles and blockage towards a steady development through education in developing countries (MoE, 2010).

The ministry of education is taking numerous measures to improve female's enrollment in the higher education. One of the measures is taking affirmative action strategies. As per the strategy, for tertiary level enrollment Ethiopian Higher Education Entrance Qualification Certificate (EHEEQC) grades favor females. That is for female's the entrance result is lower than their male counterparts. As a result, the number of female students enrolled in higher learning institutions is relatively increasing at an alarming rate (Wudu Melese \& Getahun Fenta, 2009).

Despite this fact, the findings of several researchers showed the dropout rate of female students in higher learning institutions is so high as compared with the male and even exceeds their rate of graduation (Abebayehu, 1998). Here, it seems clear that though the Ministry of Education has tried to increase the enrollment of female's in higher learning institutions; their rates of dropped out in each semester of every year is high. Thus, the problem of dropout of female students' seems worth stressing (Wudu Melese \& Getahun Fenta, 2009).

Another effort made by each University is the tutorial program that given for females of newly entered into higher though less attention is paid to implement the program in a planned, organized and supervised manner as if there was misconception and lack of interest for the program among female students, and even teachers due to various reasons (Wondiye, 2007).

Therefore, this research is proposed to identify the practices and challenges of tutorial program given for female students' in the departments of Agricultural Science, Bule Hora University.

\section{Statement of the Problem}

Investing in females and empowering them lifts entire families, communities and countries as well out of poverty. Studies carried out in cross-country are typically revealed female's education has a larger impact on economic growth than male education. These studies also confirmed investment in female is the single most effective payoff in terms of poverty alleviation and the general prosperity of a country. As females educated more, they become less get into marriage and thus early pregnancies. In addition, they are in a better position that able to negotiate the number of children they will have. Education can play a critical role in reducing violence against females and enhance their controlling power over their own bodies (Jackson, 2009).

Even though female play a significant role in the overall development of a nation, they remain under represented at all levels of education owing to different factors. For example; as stated in the education sector 
development program (ESDP IV), in Ethiopia girls'education in general and their academic performance in particular is constrained by economic, socio-cultural, familiar, personal and school factors (MoE, 2010).

On the other hand, different scholars expressed the positive impacts of a well-planned, coordinated and well organized tutorial program on academic performance of students. For instance, Fager and NWREL (2012) indicated tutorial program increases mastery of academic skills, improve self-esteem and confidence, improve student's attitudes toward school, decreases dropout rates, breaks down social barriers and creates new friendships and promotes emotional support and positive role models. Similarly, (Kebede, 2011) also noted tutorial program is beneficiary for students who lag behind their class mates in general and for female students who are in low socio economic level and need educational support than others in particular. Therefore, all schools especially for first year should implement a planned, coordinated and well organized school based tutorial program for female students.

Although all departments of Bule Hora University are providing tutorial program to improve the academic performance of female students, the departments were not put in effective as projected in a planned and organized approach. Due to this reason, the program faced difficulty to bring improvements in female students' performance. Therefore; this study is proposed to clearly assess the extent of tutorial program implementation and to identify the challenges that the programs are encountered in improving female students' academic performance.

\section{General objective}

- To assess the factors affecting implementation of first year female students in departments of Agricultural Science, BHU

\section{Specific objectives}

- To assess the challenges for implementation of the program

- To evaluate the extent of tutorial implementation

\section{LITERATURE REVIEW}

\section{Definition of Tutoring}

Different scholars defined and viewed tutoring differently. Accordingly, Kalkowski (1995) defined tutoring as a visible activity that emphasizes student leadership and responsibility, fun activities for tutors and tutees, and provides tutor appreciation and recognition throughout the school year. In line with this, Kebede (2011) citing Elliot (2002) confirmed that, tutoring is a special instruction designed to help students lead their effort to each of the track to move them up to the desired level of academic achievement. in his/her way of sharing experience ,Elliot explains that in the USA and Canada, tutoring is common at all levels of schooling from preschools though college and universities, and the practice typically involves re-teaching subjects or redesigning lesson to make the instruction clearer or more personalized for the beneficiary students.

Moreover, Wikipedia, the free encyclopedia (2013) defines tutoring program as a method of transferring knowledge and may be used as a part of a learning process. More interactive and specific than a book or a lecture; a tutorial seeks to teach by example and supply the information to complete a certain task. Depending on the context a tutorial can take one of many forms, ranging from a set of instructions to complete a task to an interactive problem solving session (usually in academia).

Besides the above definitions Powell (1997) defined Tutoring as assistance that is provided to students by non-professionals to help them attain grade-level proficiency in basic skills and, as appropriate, learn more advanced skills. Tutoring usually involves assisting with homework assignments, providing instruction and fostering good study habits. Classmates, older students, college students, academicians, professionals from other fields, parents and senior citizens can be tutors. This is referred to as peer tutoring.

Cohen, A. Kulik and C. Kulik, (1982) describes tutoring programs offered in many elementary and secondary schools today differ in an important way from yesterday's tutorial programs. In most modern programs, children are tutored by peers or paraprofessionals rather than by regular school teachers or professional tutors. They further suggest that, Tutoring programs today are open to boys and girls in ordinary classrooms throughout the country. Hundreds of teachers and researchers already have written reports on the effects of such programs on children.

In different countries tutorial is defined in different ways. According to Wikipedia, the free encyclopedia (2013), in British academic parlance, a tutorial is a small class of one, or only a few, students, in which the tutor (a lecturer or other academic staff member) gives individual attention to the students. At Cambridge, a tutorial is known as supervision. In Australian, New Zealand and South African universities, a tutorial (colloquially called a tutee or tut in South Africa) is a class of 10-30 students. Such tutorials are very similar to the Canadian system, although tutorials are usually led by honors or postgraduate students, known as 'tutors'. Therefore, all the definitions show tutorial program uses for improving academic performance of students who lag behind their class mates. 


\section{Classifications of Tutoring}

Different writers classified tutorial program in different types through different criteria. Kalkowski (1995) classified tutoring in to two major categories based on the tutor and tutee similarities and differences in age ability, grade and personal characteristics.

Peer tutoring: occurs when a tutor is of the same age, grade, or academic status as his or her tutee. These tutors are competent learners, who with minimal training and guidance, help one or more students learn a skill or concept. It is not necessary for these tutors to be experts in a particular subject for this method to be effective. This method of instruction allows student tutors to help follow students, and in turn, learn by teaching.

Cross-age tutoring: occurs when the tutor is older or in a higher grade level than the student that he or she is tutoring. Cross-age tutoring provides an opportunity for older students to serve as tutors/mentors to younger students. These tutors are engaged, challenged to learn and reinforce material taught in class, and allowed to take responsibility and an active role in the learning process. Because of the amount of preparation and responsibility that is associated with cross-age tutoring, the student tutors often gain as much as or more than younger tutees. Barely (2002) also classified tutoring into three sub-categories.

Volunteer tutoring: consist of tutors who are mostly nonprofessionals and sometimes professionals who are giving their time for merely instinct reward.

Student tutoring: consists of tutors who are different from peer tutors in that they are significantly older or otherwise advanced beyond the academic level of the tutees.

Professional tutoring: consists of a set of professionals including licensed teachers, trained specialists and paraprofessionals. The use of experienced and professional tutors give strength to the notion that professional teachers are best suited for the role of tutoring, nevertheless, it is relatively expensive than the other types.

In the same way from Wikipedia, the free encyclopedia (2010), also classified tutoring program in to student-to-student tutoring, online tutoring, home tutoring, and computer based tutoring, individual tutoring and group tutoring.

Therefore all these types of tutoring classified by different writers round to enhance students' academic performance. Besides from the above classifications of tutoring professional tutoring is implemented for female students' tutorial class in the study department.

\section{Benefits of Tutoring Programs}

In general tutoring programs increases mastery of academic skills, Improves self-esteem and confidence, Improves student's attitudes toward school, decreases dropout rates, truancies and trades, breaks down social barriers and creates new friendships and Promotes emotional support and positive role models. It also uses for the students: One on one instruction, Instruction tailored to specific learning styles and needs ,Instruction free of competition students can progress at their own pace ,Increased praise, feedback 16 and encouragement, Companionship with a positive adult role model and improved social skills. For the tutoring programs uses as a sense of pride and accomplishment for having helped someone else, Increased academic mastery (especially in cross age and peer tutor situations), Increased self-esteem and confidence, Enhanced sense of connection to their community, Valuable career related experience. For the Teachers tutoring programs uses to reduced time spent on repetitive work more time to focus on technical and professional tasks, increased monitoring of individual students, Personal gratification in witnessing the success of their students (Fager and Nwrel, 2012)

\section{Purpose of tutoring}

According to teaching chemical information of America, 1997; Tutorials are generally intended to:

- Help students to gain a deep understanding of the subject matter in their discipline - discussion in tutorials helps students to see the significance and implications of their knowledge so they can apply what they have learned in new contexts; students should also develop a healthy skepticism about the literature.

- Enable students to learn how to think, for instance to synthesize disparate sources, to formulate a thesis and justify it, to anticipate criticisms of their arguments, and to respond to questions and challenges thinking 'on one's feet' - in the tutorial setting.

- Develop students' basic academic skills (e.g. identification and evaluation of relevant resources, effective communication both orally and in writing, effective time-management, critical selfassessment).

- Enable students to pursue their individual academic interests within the context of their subject.

- Develop students' ability to think and act like a professional in their discipline, like a classicist, mathematician, historian, scientist, or social scientist, rather than like a student 'covering' a syllabus in classics, Mathematics, history or a science.

- Foster a close relationship between student and tutor over the course of the academic degree, thereby personalizing students' university experience and supporting students' overall personal development 
throughout their student career.

\section{Outcome of tutoring}

According to Powel (1997) four general positive outcomes of tutoring programs are:

- Tutoring can improve student performance and skills, and provoke student interest in participating fully in the educational process.

- Tutoring benefits can improve the learning of both the tutor and the tutee.

- Tutoring can relieve the strain on teachers of trying to teach large, often mixed-ability classes.

- Tutoring is relatively inexpensive and greatly enriches education.

\section{Importance of female education}

According to Helena, (1996) Female education

$>$ Enhances their participation in national development

$>$ Improves their states in life

- Given them self-confidence to take independent decisions and stand by them

- Improves their self esteem

- Enables to stand up for themselves and achieve greater self-fulfillment

- Make them aware of civic rights

- Make them to contribute more effectively to social and economic development of the society

Brings about better health as future mothers as an educated mother can raise a healthier family because

- She keeps healthier her self

- She knows about nutritious foods to increase life expectancy of the future generation she knows how to respond to health related emergencies.

- She improves child rearing and development by attending to the health of the children and caring all for them.

Brings about smaller families because educated we men tend to

- Accept family planning practices because they understand and so reduce birth rates and so have fewer children.

- Marry late because of the time they spend at school so have fewer children.

Brings about greater national productivity because females who are educated

- Have better employment and so earn more income to improve the status of the family.

- Contribute ideas to national development

\section{RESEARCH METHODS}

\section{Data collection}

Data were collected from both students and staff members to assess those factors affecting the implementation of tutorial program for first year Animal and Range Science, Plant Science and Natural Resource department. As a result, a total of 40 students and 10 instructors were considered. To collect data questionnaire and interview were used.

Questionnaire: open-ended and close-ended questionnaire were used for students.

Interview: A semi-structured interview was made with instructors in order to determine why they were not properly implement tutorial program and the problems they were faced during time of implementation.

\section{Data analysis}

The data collected through questionnaires and interview were tabulated and analyzed using simple descriptive statistics such as mean and rank to assess those factors affecting the implementation of tutorial program.

\section{RESULTS}

This part deals with the presentation, analysis and interpretation of the data gathered through various instruments. The analysis were involved both quantitative and qualitative data analysis techniques. The quantitative data analysis was carried out on the results obtained through the questionnaire. The qualitative one was held on the data obtained through interview. A total of 40 students and 10 instructors were randomly selected from all class year in faculty of Agricultural Science. The results of the analysis made are presented hereunder.

\section{Responses of Female Students to Problems Encounter in BHU}

Students were given the list of 7 possible problems that female students in Agricultural Science Faculty may face to rank in order. The responses are summarized in the appendix table. The result presented in Table 1 was revealed that being placed in the department they are not interested is the first problem females' face in Agricultural Science Faculty. The second problem was found to be fear of failure. Lacks of facilities were found 
to be the third problem that challenges female students while lack of security in and around the University was ranked as fourth problem. The remaining problems such as verbal and physical harassment by male students and by some instructors, economic problem and homesickness were ranked as the problems female students encounter in Agricultural Science Faculty from fifth to seventh respectively. The results of the current study were confirmed that the school climate may act as a threat to female students while unfavorable social climate was likely to distract the female students from the task at hand, to detriment of performance and to influence their self-concept.

\section{Responses to Factors for Low Achievement and Causes of Attrition}

The results presented in Table 2 show that these problems were ensued from perception of students while the remaining factors were from the environments that contributes for female students' low academic performance and higher attrition to the less significant factors. The current findings were proved that the greater support female students receive from male students and teachers, the higher is their academic performance. The tutorial programs that promote self-efficacy, self-confidence, and high expectations are as important as programs that provide opportunities for higher academic achievement and the success of female students while personal problems such as fear of failure and lack of self-confidence are the top most factors that impede female students' academic achievement in BHU.

\section{Factors that Discouraged the Implementation of Tutorial Program}

The findings revealed that there were five major factors that induced reticence among the students (Table 3 ). Limited course coverage in tutorial was ranked first in the list of most frequent factors mentioned as discouraging the implementation of tutorial program. Students reported that the tutorials were commonly given when exam come up while negative classmate traits of few students out of class affect the participation of other students in the programs. Many of the senior students interviewed were expressed their displeasure regarding not having tutorials which might direct females for dropout. On the other hand, lecturers were mentioned negative traits like having poor teaching skills, being impatient and unapproachable deter students from participating in tutorial program and thus discouraging the implementation. These lecturers felt that unattractive incentives were made them less participative in tutorial program. Non-concerned body in particular was ranked fourth in the list of most frequent factors mentioned as discouraging the effective implementation of tutorial program. Some of the instructors were not strives truthful for BHU tutorial standards, 15 hours which might be followed by concerned body. Uninteresting and difficult class content was the eighth mentioned factor hindering implementation of tutorials. Students were faced difficulties in understanding class content that was difficult and they lost focus when it was uninteresting.

\section{ACTION PLAN, STRATEGIES AND IMPLEMENTATION}

\section{Action plan}

Students and teachers were also asked to answer about the types of affirmative action should be given in the faculty. Their responses were revealed the following in order from more frequently employed affirmative action strategies to less frequently implemented ones. These include:

- Giving additional tutorial sessions for senior female students.

- Giving awareness training.

- Giving assertive training.

- Giving priority for females to select the field of study they need.

- Educating females about their rights and

- Establishing laws and regulations that will prevent female students from different forms of attacks.

Finally if these strategies are properly implemented, the problems female students encounter in and the factors that affect female students' academic performance that cause high attrition will be minimized.

\section{Implementation}

The first step was the discussion with female students on "how tutorials can effectively be implemented?" The brief presentation was made for two hours as shown in the table below.

Activities and time: Presentation about the topic by teacher for about 30 minute, Group discussion on a topic presented for 30 minute, Students will present what they have discussed for 30 minute while the remaining 30 minute will be allocated for comments and conclusions.

The second step was observing a change of female students' for effectively implementation of tutorials after training and awareness creation. And the first chance will be given to female students to help them to actively participate.

In the third step, each students will took training about the contribution of effective tutorial and henceforth create an open ground for students to ask vague and unclear ideas. 
Fourthly, an in depth tutorial will be given for students who have misconception about female tutorials and how to work together with faculties will be discussed. Finally, the floor will be opened to reflect their new ideas while a general comments and encouragements will be arranged with the students on their progress.

\section{SUMMARY AND CONCLUSION}

The main purpose of this study was to investigate the factors affecting implementation of first year female student's tutorial in Agricultural Science Faculty which may direct female students' for low academic performance and high attrition. In order to examine the factors both quantitative and qualitative research methods were employed.

The findings of the study indicated that the problems female students encounter in Bule Hora University constitute personal, environment, economic and family related problems. The factors that affect female students' academic performance and cause high attrition are categorized in the same way as problems of female students encounter. They include personal matters, lack of self-confidence, lack of adequate effort, carelessness, lack of ability to be competent and previous academic background in high school.

The interviews made with teachers were revealed negative taboo by students and some instructors is the major factor for low academic performance of female students and proper implantation of tutorial program in BHU while interviewers indicated the types of affirmative action should be practiced. The results were also suggested students and lecturers play pivotal roles in implementing tutorials effectively while negative traits were the factors identified as a damper to students' benefits from the program.

In conclusion, the majority of problems female students encounter and those factors that affect female students' academic performance are personal and the other problems are caused by the university environment. Furthermore, the factors that affecting implementations of tutorials and thus affect the attrition rates of female students.

\section{REFERENCES}

Abebayehu Aemero (1998). Problems of Gender Equity in Institutions of Higher Education in Ethiopia. In Amare et al. (Ed), Quality Education in Ethiopia: Vision for the $21^{\text {st }}$ century. Addis Ababa: Institute of Educational Research.

American Chemical Society (1997). CINF Workshops of Teaching Chemical Information Tips and Techniques.

Barely, Zoe. et al. ,(2002). Helping at risk students meet standards Midcontinent research for education and learning (MCREL) aurora retrieved on 22 December from http://www.Mcre;org/topics/Instruction/products/116/

Helena R. Asamoah-Hassan, (1996). Importance of female education: being a lecture delivered to students of the Kumasi girls secondary school on Friday the 21st of June 1996.

Jennifer Fager and NWREL, (2012). Tutoring: Strategies for Successful Learning" Seattle Public Schools Volunteer Services.

Kalkowski, p, (1995). Peer and cross-age tutoring; School improvement research series; Close-up \#18. Portland, OR: Northwest Regional Educational Laboratory. Available online: http://www.nwrel.org/scpd/sirs/9/c018.html.

Kebede Tefera, (2011). The practice and major challenges of school based tutorial program for female students in Dembecha Woreda of West Gojjam Zone. MA thesis AAU.

Leah Witcher Jackson, (2009). Educate the Women and You Change the World: Investing in the Education of Women is the Best Investment in a Country's Growth and Development: Forum on Public Policy, Baylor University School of Law.

M. Anne Powell, M.S.W, ( 1997). Academic Tutoring and Mentoring: A literature review: CRB California Research Bureau, California State Library.

Ministry of Education,(2010). Education Sector Development Program IV ESDP IV (2010/2011-2014/2015) Program Action Plan /PAP: Addis Ababa.

Peter A Cohen, James A. Kulik and Chen-Lin C. Kulik ,(1982). Educational Outcomes of Tutoring: A Metaanalysis of Findings:American Educational Research Journal http://aerj.aera.net.

Wikipedia, the free encyclopedia, (2010). Tutorial: last modified on 14 November 2013 at 22:27.

Wondiye Kebede, (2007). The practice and major challenges of school based tutorial program for female students the case of primary level 2nd cycle government school of Addis Ababa.

Wudu Melese \& Getahun Fenta (2009). Trend and causes of female students' dropout from teacher education institutions of Ethiopia: the case of Jimma University 


\section{Appendices}

Table 1: Problems Female Students Encounter in Agricultural Science Faculty

\begin{tabular}{|l|c|c|}
\hline \multicolumn{1}{|c|}{ Problems in the University } & Rank & Remark \\
\hline Being placed in the department they were not interested & 1 & \\
\hline Fear of failure & 2 & \\
\hline Lack of facilities (separate reading places, medical, recreation, etc) & 3 & \\
\hline Lack of security in the University and around & 4 & \\
\hline Verbal and physical harassment by male students and instructors & 5 & \\
\hline Economic problem & 6 & \\
\hline Homesickness & 7 & \\
\hline
\end{tabular}

Table 2: Responses to Factors for Low Achievement and Causes of Attrition

\begin{tabular}{|l|c|c|}
\hline \multicolumn{1}{|c|}{ Problems in the University } & Rank & Remark \\
\hline Poor high school performance & 1 & \\
\hline Lack of adequate effort & 2 & \\
\hline Carelessness & 3 & \\
\hline Difficulty of education & 4 & \\
\hline Lack of proper guidance & 5 & \\
\hline Tension & 6 & \\
\hline lack of self confidence & 7 & \\
\hline
\end{tabular}

Table 3: Factors that discouraged the implementation of tutorial program

\begin{tabular}{|l|c|c|}
\hline \multicolumn{1}{|c|}{ Problems in the University } & Rank & Remark \\
\hline Limited offered course & 1 & \\
\hline Giving tutorials as exam come up & 2 & \\
\hline Negative classmate & 3 & \\
\hline Absence of tutorials for senior female students & 4 & \\
\hline Unprofessional traits of instructors & 5 & \\
\hline Unattractive incentives & 6 & \\
\hline Non-concerned body & 7 & \\
\hline Uninteresting and difficult class content & 8 & \\
\hline
\end{tabular}

